\title{
Understanding Teacher Trainees' Reasoning Patterns about the Formation and Description of Chemical Compounds
}

\author{
Ruby Hanson ${ }^{1 *}$ Nelly Sakyi-Hagan² \\ ${ }^{1}$ Department of Chemistry Education, University of Education, Winneba, Ghana, ${ }^{2}$ Department of Integrated Science Education, University of \\ Education, Winneba, Ghana
}

*Corresponding Author: maameruby@yahoo.com

\section{ABSTRACT}

In this study, diagnostic worksheets adopted from the Royal Society of Chemistry and microscale chemistry activities were employed to investigate teacher trainees' understanding of chemical compounds. The framework for the study was hinged on the constructivist

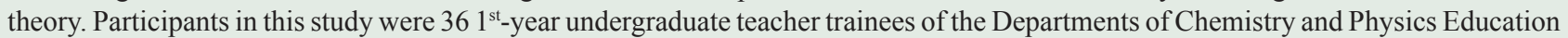
in the University of Education, Winneba. One group was taught through the use of worksheets, while the other was engaged through traditional exercises, but all participated in microscale activities. A pre-test to assess homogeneity of the groups showed a common performance entry point. It revealed that trainees had language-based problems, conceptual misunderstanding, and poor interpretation of chemical formula. Post-test and retention test showed significant differences between groups. The group that used the worksheets, though simple, outperformed the traditional group. Thus, the study concluded that the use of diagnostic worksheets affects trainees' understanding of principles required for the formation of chemical compounds and enhances retention $(t=20.6 ; \rho<0.05)$. This study was significant because trainees must gain exposure on how to develop sound scientific concepts through innovative ways to help their own students to break the vicious cycle of chemical misconceptions

KEY WORDS: chemical compounds; diagnostic worksheets; teacher trainees; reasoning patterns

\section{INTRODUCTION}

I

n a traditional classroom, a teacher introduces a concept by explaining a theory without incorporating students' views for a balance (Sam et al., 2016). Attempts to find out and challenge students' prior knowledge are rare in such traditional settings. Open discussions and formal peer interactions are not normal routines. Thus, learners memorize and regurgitate information without adequate reflection, deconstruction, construction, and reconstruction procedures that are required for concept formation. This makes the important learning process of personal development and accommodation of scientific views, a challenge to learners, who often develop alternative conceptions of chemical principles. To foster conceptual change, students have to be confronted with differing or inconsistent events that contradict their own naïve perceptions, such that a disequilibrium or cognitive conflict will result and initiate them into a reflective and resolute condition.

Constructivisim, as an educational practice, gives students the opportunity to engage in activities that enable them to construct their own meaningful concepts. They are able to acknowledge their faulty conceptions and upon reflection disregard (i.e. deconstruct) them or build a connection (balance) between the old and new concepts. As they acknowledge their faulty conceptions on reflection and disregard (deconstruct) them or build a connection (balance) between the old and the new. Studies have shown that learning can be better achieved by constructing knowledge as a result of one's own interaction with the environment (Vermette, et al., 2001; Hanson, 2016). This interaction with the learning environment must be done in an interactive, fun-filled, colorful, and memorable manner to promote concept visualization. Some of the times, social representations could be employed so that students can link what they see with events that they can remember. According to cognitive theorists, students construct concept-representation connections by relating visual features to meaningful referents (Schnotz, 2014). Visualization has been identified as one of the key innovative strategies to understand chemistry concepts (Jones and Kelly, 2015).

Hake (1998) clearly distinguishes between traditional and other innovative strategies of teaching. According to Hake, the traditional method does not allow learners the freedom to explore on their own to form, test, and retain knowledge as other methods would. He describes the "other" methods as those that are not only innovative and unlike the "traditional" method but also engaging and highly interactive. In recent times, Hake's idea has been widely accepted and practised by educators, especially science educators (Yakmaci-Guzel and Adadan, 2013; Kihwele, 2014; Toman and Ergen, 2014; Hanson, 2017; Chanyoo et al., 2018). it is anticipated that using interactive resources such as concept maps, worksheets, puzzles, and hands-on activities to engage learners in their study of chemical compounds and their formation, could be a booster to enable conceptual understanding. 
about chemical compounds and their formation could be a booster to enable conceptual understanding. The use of concept cartoons, though simple and inexpensive, has been used successfully in teaching about the structure of matter first, before proceeding on to how matter combines in different ways (Say and Ozmen, 2018). These latter authors assert that, to address problems in the learning and understanding of fundamental concepts in chemistry, new and alternative teaching methods and the use of engaging materials must necessarily be employed.

To understand how chemical substances react so that they can be correctly represented in symbolic form, as expected, the chemical reaction process has to be well understood. This chemical reaction pathway actually involves thermodynamic processes but could be simplified through animations, concept mapping, worksheets, and hands-on (macro) laboratory activities. In all of these efforts, the significance of chemical symbols and formulae would have to be appreciated and the relationships between macro, micro, and symbolic representations emphasized. This is one aspect that students find difficult to understand, as they have challenges with forming authentic mental models about the various representational concepts of matter (Hanson, 2016). Yet, it a very critical requirement and a bridge to a successful interpretation of what truly happens during chemical reactions.

I would argue that the prediction, description, and explanation of chemical reactions are fundamental in chemistry education. Oftentimes, students do not understand the particulate model of matter or the principles of chemical bonding, which are pre-requisites to understand compound formation. Thus, intuitive assumptions inappropriately guide students' thinking about chemical phenomena (Talanquer, 2006). Sometimes, commonsense ideas are used to make sense of phenomena. These commonsense ideas are often difficult to deconstruct because they have been with learners quite early in their lives and have been seen as "logical" and therefore acceptable to them. Teachers have to be aware that basic learning theories would be required to enable learners to undergo such deconstructions of their misconceptions and reconstruction of more authentic concepts. For example, with regard to applying the constructivist theory, it is possible to change from preconcepts which are non-scientific to scientific concepts if learners would be given the chance to construct their own learning structures actively so that conceptual growth could occur in accordance with Piaget's assimilation or, perhaps, conceptual change occurs congruent to Piaget's accommodation. It is clear that teachers need to equip themselves with learning principles so that they could be better facilitators in the field of teaching, especially with the sciences and chemistry, in particular, where learners are expected to move within the chemical triangle of nature of matter. Quite often, even tertiary students find it difficult to explain events that occur during simple chemical processes such as neutralization and compound formation because they cannot make the transition from the macroscopic tangible level directly to the representational level (Demircioglu et al., 2005).

Many research studies have investigated how students understand chemical reactions as well as the bonds that break and reform during reaction processes (Yan and Talanquer, 2015; Barke et al., 2009). Findings from these studies reveal that students do not explain chemical reactions in terms of chemical interactions among submicroscopic features of reactants and products to predict the outcomes of chemical reactions (Talanquer, 2008; Hanson, 2017) as required on the thermodynamic level. Besides, if they seem to understand, it may only be superficial as later or delayed assessments show that their understanding was not deep-rooted. Delayed assessment of learners after an innovative instructional design and practice or otherwise could enable teachers to find out if taught concepts have been retained by learners. Some innovative practices which have been found to enhance retention of concepts are microscience (or microscale) activities, conceptual laboratories, problem-based learning, computer-assisted learning or multimedia learning, conceptual assessment, concept cartoons, concept maps, mind maps, role play, and worksheets. All of these approaches or techniques are very good, but a theory must drive their use.

Worksheets have been found to be effective resources which fall in line with the principles of constructivism (Vermette, et al., 2001) and have been used in this vein to reduce conceptual errors (Celikler, 2010; Yildrim et al., 2011; Hanson, 2017). They are simple diagnostic tools or resources that contain process steps which encourage learners to structure knowledge and allow for full in-class participation. This instils in them a responsibility toward their own learning, as they gain scientific process skills. Worksheets are also cheap to supply to all students, besides enabling free expression of thoughts. However, limited literature is found about the effect of worksheets on students' academic achievements. The literature that was able to be reviewed, report positive findings about usefulness and practicality of worksheets and how they have the potential to promote conceptual growth among students (Celikler, 2010; Demircioglu et al., 2005). Some researchers have suggested the use of practical work and information and communication technology to teach the topic of chemical bonding and formation of compounds (Hanson, et al., 2017). These standard strategies may be costly and unattainable for institutions in some developing countries that have minimal resources and infrastructure to afford chemicals, water, equipment, power supply, and computers. Thus, worksheets could be a first option toward the integration of constructivism in classrooms to facilitate student-centered learning. In their use of worksheets, students get steps to transactions but with responsibilities. Worksheets help them to gain scientific process skills as they oftentimes may be required to set up experiments on their own, record data, and interpret and conceptualize ideas. These foster the acquisition of skills such as comprehension, critical thinking, analytical, deductive, and social collaborative skills. 
Practical laboratory or hands-on classroom activities have also been found to enhance the formation of scientific concepts among learners of science and chemistry, in particular. This is because, apart from learners constructing their own knowledge through practice, visualization, and association, it enhances concept formation and retention. There is no doubt that handson activities are the best practice for learning science, as they make students feel like scientists and enable them to build their own concepts from firsthand experiences. However, the cost of obtaining equipment and chemicals, especially for chemistry activities, is not only exorbitant but also comes with its own risks. This problem can be addressed by minimizing the use of chemicals through the use of a microscale equipment (MSE). MSE has been used in America, South Africa, Malaysia, Taiwan, and other parts of Asia with great success. Due to the cost and time required in constructing standard science laboratories, as well as other running cost such as water and electricity, most institutions across the world have resorted to the use of MSE (Hanson, et al., 2011; Sebuyira, 2001; Supasorn, 2015; Zakaria et al., 2012). Gebrekdian, et al. (2014), carried out studies in Ethiopia that involved the use of small-scale chemistry hands-on approach in secondary schools and found that the activities were viewed by both teachers and students as cost and time-saving, safe, easy to use, and enjoyable. Hanson et al. (2011), Supasorn (2015), and Zakaria et al. (2012) also made similar observations in studies where they employed the use of microchemistry equipment. Microscale science is linked with green chemistry to conserve the environment. The awareness of avoiding damage to ecology and health has helped in promoting a better image of science and chemistry, in particular, in recent years.

The conceptual framework for this study was based on the constructivist theories that require that learners construct their own meaning of events around them as they analyze events for patterns of logical understanding through reasoning. Constructivism is a revolution in the educational field that originates from the works of Piaget and Bruner. Constructivism emphasizes the importance of active involvement in a top-down learning approach where often complex situations/tasks are presented and basic skills are taught and learned during the solution or unraveling session and constructing personal knowledge. A teacher, therefore, needs a very good understanding of what children know when they come to the classroom.

\section{PURPOSE OF THE STUDY}

The study investigated the possibility of using simple diagnostic worksheets as a complement to MSE (in which trainees are familiar with), to teach the topic "chemical compounds," and to assess its effectiveness in enhancing retention. It specifically sought to find out some if students had prior misconceptions about compound formation (macroscopically) and how they were expressed on a representational level. The study further sought to find out, interpretatively, if there were any underlying causes or emergent factors for identified reasoning patterns among teacher trainees.
The study was guided by three research questions:

i) What are some of the common student reasoning patterns about representations of compounds?

ii) What is the possibility of using worksheets to enhance the teaching and learning of the concept of chemical compounds?

iii) What would be the retention rates of students taught using the innovative worksheets and those taught with the traditional method?

\section{METHODOLOGY}

The population for the study comprised all level 100 teacher trainees from the Science Departments of the University of Education. The sample (referred to as participants or trainees) consisted of twelve chemistry major teacher trainees and 24 non-major teacher trainees from the 2014/2015 academic year. A pre-test (Appendix A) was administered to all participants to assess the homogeneity of their entry knowledge. It was necessary to assess the homogeneity of both groups to ensure that none of the groups had an upper hand or advantage over the other. After the pre-test, all the participants were allowed to engage in a practical activity that required the use of microscale equipment (MSE) to confirm familiarity with its use. A quasiexperimental method was employed in this study after the pretest. The 24 non-major (Minor) teacher trainees who formed the experimental group and were a slightly weaker class were taught with worksheets (Appendices C-E), while the major group of twelve teacher trainees was taught by the traditional method. The major group formed the control group, while the minor group formed the experimental group. This was because it was more appropriate to engage the "weaker" group in a supposedly newer and more beneficial teaching strategy so that both groups could possibly be at par by the end of the study period. Both groups used MSE in their practical hands-on activities so that each trainee could have access to their own work equipment and chemicals and learn through practice, association, and accommodation (Barke et al., 2009). Besides, the use of the MSE was to ensure the trainees worked in a safe and sustainable environment without damage to ecology, even as they employed the use of chemicals.

A post-test and a retention test (Appendix B) were administered after 2 and 3 weeks of treatment, respectively, to assess the trainees' gains in knowledge. The post-test contained items which were a remix of the pre-test questions. The retention test was of a similar format and consisted of ten items. Each test was scored over 20 marks. The obtained data were analyzed to assess the effectiveness of the newly introduced worksheets. The effect of the MSE was not critically assessed as a contributing factor to the outcome of the study as it was a common tool for both participating groups and expected to give possible similar outcomes in performance (Supasorn, 2015). In this vein, the control group was exposed to blackboard illustrations (where possible) and symbolic representations plus microactivities, while the experimental group used worksheets and microactivities. It was expected that color changes that 
could occur during the practical (hands-on) activities would enhance visualization and connect what the trainees saw to their retention capabilities. Trainees in each group were $<30$ and so non-parametric tests were used (Yildrim et al., 2011).

Data were collected through pre-test, post-test, and retention test. These data were analyzed quantitatively and interpretively. The first author analyzed all the trainees' worksheets and smallscale (micro) laboratory reports on an interpretive level for a worthwhile discussion with the second author. The coauthor analyzed about $60 \%$ of the trainees' worksheets and laboratory reports. This was necessary to ensure cohesion in observations made by the two authors. Any differences that arose were resolved by mutual agreement or otherwise, amicably. These were analyzed by means of descriptive means with the SPSS Version 20 statistical package. Informal observations were made while the trainees carried out their activities on "chemical compounds."

\section{RESULTS AND DISCUSSION}

The analyzed results for the pre- and post-test scores are shown in Table 1

From Table 1, it is observed that trainees' entry performance was about the same $\left(\mathrm{N}_{24}=4.79 ; \mathrm{N}_{12}=5.42\right)$. The pre-test $\rho=0.67$ implies that there was no statistical difference in academic conceptions about chemical compounds between the experimental and control groups' entry points in this study as the $\rho$-value was $>0.05$. Trainees in both the groups showed poor identification of reacting ions and molecules as well as particles that formed products. Ions and molecules were used interchangeable with no clear distinction. They were also not able to identify that chemical changes had occurred in instances where chemical compounds had been formed. Some trainees chose to say that they were physical changes because the same "elements" that were in the reactants were found on the product side. The different kinds of combinations and the chemical bonds between them were lost on the trainees. Attempts at diagrammatic presentations of the chemical processes were not encouraging either.

However, it was observed that there was a statistically significant difference between the success of the groups when the post-test results were compared. The trainees' posttest scores showed improved results with mean scores of $\mathrm{N}_{24}=13.75$ and $\mathrm{N}_{12}=11$. Analysis of statistical differences was not extremely large, but yet statistically significant as it showed a positive change from their entry point (0.67), with a new $\rho=0.03$, slightly less than the set value of 0.05 at a $95 \%$ confidence interval. There was a decrease in the rate of alternative conceptions or wrong analytical responses, especially within the experimental group, more than in the control group. Analysis of post-test sheets showed that the trainees in both groups, but more with the experimental group, could explain their basis for choosing to say that a chemical compound had been formed. They used appropriate scientific language such as "physical process," "chemical process," "chemical change," "ionic bond," or some other chemical bond in their explanations for statements or choices made. They further came up with expressions such as "a new substance has been formed and so a chemical change occurred" and "heat energy was given off in the reaction that I performed and so most likely a compound has resulted." From their worksheets, they were able to deduce that diagrams of say $\mathrm{CS}_{2}$ and $\mathrm{NH}_{3}$ depicted compounds even though different elements contributed to their formulae, as they each had more than one type of atomic core. There were a few instances where some trainees had difficulties figuring out mixtures that presented molecules, such as a diagram showing a mixture of $\mathrm{S}_{8}, \mathrm{C}_{2}$, and $\mathrm{CO}$ as individual entities; yet, a majority of the trainees were able to make out the true identification of the model given. They were able to write out the chemical formulae correctly, such as for chloride, and correct oxy-anions for the carbon, nitrogen, sulfur, phosphorus, and chlorine elements. The terms "nitrate" and "sulfate" were used indiscriminately, while sulfide, sulfite, nitride, and phosphines were used more appropriately with supporting reasons. Since the only new factors in learning that the trainees performed were the enhanced MSE activities and worksheets, changes in their performance could be attributed to these new factors that were introduced. However, the change between the two groups could be attributed solely to the worksheets since the use of MSE was common to both.

After a lapse period of 2 weeks of further treatment, results from a retention test showed that the experimental group that used the worksheets maintained their improved performance over the control group by a statistical difference of a $\rho$-value of $2.5 \times 10^{-12}$, at the same set parameters. The results of the retention test for both the experimental and control groups are shown in Table 2.

From Table 2, there are significant differences between the two groups of trainees whose entry performances were the same. This observed change among the experimental group could singularly be attributed to the worksheets. The use of worksheets, though simple, significantly improved the performance of trainees in the experimental group than those in the control group who did not use the worksheets. Standard deviation values indicate that scores among the trainees in

Table 1: Trainees' pre-test and post-test scores

\begin{tabular}{lccccc}
\hline Group & $\mathbf{n}$ & Pre-mean score & Pre- $\boldsymbol{\rho}$-value & Post-mean score & Post- $\rho$-value \\
\hline Control & 12 & 5.42 & 0.67 & 11 & 0.03 \\
Experimental & 24 & 4.79 & & 13.75 & \\
\hline
\end{tabular}




\begin{tabular}{|c|c|c|c|c|c|}
\hline Test & Group & n & Mean \pm SD & $\mathrm{T}$ & $\rho$ \\
\hline \multirow[t]{2}{*}{ Retention } & Control & 12 & $10 \pm 3.13$ & 20.6 & $\rho<0.05$ \\
\hline & Experimental & 24 & $17 \pm 1.42$ & & $\left(2.5 \times 10^{-12}\right)$ \\
\hline
\end{tabular}

the experimental group were all clustered around 17, with differences of about 1.42 between scores. However, there was a larger variation (3.13) among scores of the trainees in the control group.

This study sought to test whether there could be a statistical difference in conceptual output and reasoning patterns between trainees if different teaching materials were used. It also sought to find out if types of teaching materials could affect the retention rates of learners. Findings showed that though both groups were exposed to MSE practical activities to enable them to understand how compounds were formed on a macroscopic scale for further deduction at a particulate level, the experimental group performed better after the lapse period, due to the extra engaging practice with worksheets that had colorful images which depicted changes in formula units that occurred between reactants and newly formed compounds. These helped the trainees in the experimental group to form better mental models of their expected compounds, even though they were also not visually privy to microscopic combinations of atoms. Yet, the reacting elements, ions, or molecules which were colored and also further enhanced their understanding about how different particles could lead to new compounds. The post-test results did not yield much statistical significant difference between the two groups, as the MSE has been proved in other studies to affect students' conceptual understanding positively. The MSE could, therefore, have affected the gains in performance and conception in the posttest among both groups, as observed in other studies (Supasorn, 2015; Yitbarek, 2012; Zakaria et al., 2012; Sebuyira, 2001). However, the higher performance among trainees in the experimental group over those in the control group, judging by their individual entry means, could be attributed solely to the worksheets (Celikler, 2010) which was the only different variable among the sample.

The obtained results are consistent with findings made by Hanson (2016), Zakaria et al. (2012) and Celikler (2010). The formation of vivid and colorful mental models has been found to be possible if students are exposed to colorful as well as simulated impressions of chemical species. Color and images were useful in helping undergraduate students to understand the concept of stress effects on equilibrium in a recent study (Hanson, 2016). Analysis of the trainees' worksheets in the current study revealed that they understood that a cation must necessarily be represented before an anion at the representational level, as scientifically accepted. In other words, they were able to show correct symbolic representations of species at the representational level. However, representations of the anionic part in word form were a challenge possibly because the trainees could not conceive proper models of anions and their names.

Anions such as nitrates, nitrites, and nitriles as well as sulfates, sulfites, and sulfides were not represented correctly nor differentiated appropriately when reasons were required to be assigned for the choice of names, especially in the pre-test and shortly before remediation commenced. A nitrate $\left(\mathrm{NO}_{3}^{-}\right)$ was named as a nitride, nitrite, or nitrile. Other nitroxides and ions such as $\mathrm{NO}_{2}, \mathrm{NO}_{2}$, and $\mathrm{NO}$ could all be named as nitrate. Oxides of phosphorus were named as phosphoric, phosphorite, or even phosphite. Oxyacids of the halogens, nitrogen, phosphorus, and sulfur were mostly named wrongly if trainees were presented with their formulae. This challenge was more evident among the control group that did not use the worksheets. It was obvious that the trainees who showed a mixup over the names of these species missed out on the principle that said that the number of oxygen atoms that were attached to the central nitrogen atom determined the name of an oxyanion. As indicated earlier, sulfur oxides were represented and named with difficulty by trainees in the control group. Species such as $\mathrm{SO}_{2}, \mathrm{SO}_{3}$, and $\mathrm{SO}_{4}{ }^{2-}$ were all named as sulfates. Sometimes, they were disulfur oxide, sulfur (II) oxide, sulfur (III) oxide, and sulfur tetraoxide, respectively. An individual could also name all of such examples as sulfides, sulfites, or sulfates with no distinguishing explanations. If explanations were attempted, then they were weak ones that said that the attached oxygen (to the sulfur atom) made a sulfide or other. A minority group in the control group failed to clearly state the principles that were required for compound formation when given sets of anions and cations. For example, they adduced that compounds could be formed from "two identical" elements, atoms, or ion. When prompted to explain what they meant by the descriptive word "identical," it was difficult for them. They clearly had no basis on which their assumption was made. One female trainee intimated that "they could be from similar groups." Further probes indicated that she was referring to species from a "cationic group" and an "anionic group." By cationic group, she meant a species from Group 1, while by anionic group, she referred to species from Group 17. Clearly, the conception of this trainee was indistinct. This trainee from the control group had a wrong mental model of species that could come together to form an electrovalent compound. There was no difference between the two groups' understanding and application of the periodic parameters. Such a wrong conceptual model was also identified by Say and Ozmen (2018) when they used concept cartoons to elucidate $7^{\text {th }}$-grade students' understanding of the structure and properties of matter.

In the current Ghanaian study, if the teacher trainees were presented with the name of a compound such as trioxonitrate to express in the representational or symbolic form, they were unable to do so, as they had challenges with the application of the IUPAC nomenclature. IUPAC nomenclature is introduced to Ghanaian children in the $8^{\text {th }}$ grade or what is commonly known as Junior High school 2. Students are introduced to oxidation numbers as well as how to work them out for 
individual species in the given formula. After that, based on their knowledge about names of at least the first 20 elements, they are taught the principles of naming compounds. It is at first surprising to note that they cannot do any of these when they enter the universities after Grade 12. This crop of trainees was not familiar with common names perchlorate, chlorate, chlorite, or hypochlorate for oxyanions of chlorine, as discussed for nitrogen, phosphorus, and sulfur in earlier submissions. Studies in the past have shown that most of these Ghanaian students only learn about some basic reactions and the subsequent outcomes by rote and not on principles (Hanson et al., 2011). Thus, during the remediation process, especially with the control group, trainees had to be taken through pictorial exercises where the particulate nature of reactants was depicted diagrammatically to show how they "broke up" and "re-joined" through ionic bonding to form new compounds were shown. Basic questions such as "how many chloride ions are bonded to each silver ion in silver chloride" were asked when trainees were to carry out a chemical reaction to form silver chloride from sodium chloride and silver nitrate. Then, the turning point question came up, where they had to give answers for their (correct) observations, if they could. In this particular exercise, the microactivity was also carried out, so the evidence of a precipitate $(\mathrm{AgCl})$ from two non-precipitant reactants could be easily observed and appreciated by the trainees that a new compound had been formed.

The trainees' challenges could be attributed to their inability to form proper conceptual mental models, regardless of the practical activities that they engaged in. To understand how compounds are formed, learners must first understand how chemical reactions occur, how bonding occurs, how molecules interact, and what determines whether an interaction would be favorable or not; only then, can the outcome of the compound to be formed be determine. This chain of processes is oversimplified at lower grades and sometimes also taught in a rote-like manner by teachers who never understood the underlying principles of compound formation. Factors such as the thermodynamic processes involved, the nature of reacting species, the compatibility, and the feasibility of all must be considered. Talanquer (2008) carried out a study to find out the extent to which learners intuitively use an additive framework to predict the properties of a chemical product, rather than an approach that recognizes the emergent nature of the properties of chemical compounds. He found that most students relied on an additive heuristic to predict the properties of chemical compounds. They overlooked the possibility of emergent properties that could result from the interactions of atoms that composed the system. He suggested that teachers provide diverse opportunities for learners to identify properties in a variety of contexts.

The experimental group performed relatively better in writing word formulae and matched them correctly with their symbolic forms. This could also be related to the observation that they learned to associate word and symbolic formula (microscopic models) with images (macroscopic models) in their minds. The worksheets afforded the experimental group, the opportunity to participate in lessons more actively through the expression of individual thoughts, thereby taking responsibility for their actions and forming decisions through them. Thus, meaningful learning was achieved as per the constructivist paradigm. This led to the ingrain of permanent learning which was confirmed through results from the retention test. There is, therefore, a high possibility of using worksheets to improve learning outwardly and certainly momentarily. This possibility was confirmed when the trainees in the control group were introduced to pictorial diagrams on their board during remediation. In this exposure, they were taken through processes to appreciate the conceptions of elements and mixtures such that they were able to distinguish them from elements using atomic and molecular cores (nuclei). Similar observations where interactive approaches enabled the formation of mental conceptual models were made by Hanson (2017), Celikler (2010), Toman and Ergen (2014), Yakmaci-Guzel and Adadan (2013), and Yildrim et al. (2011).

The difference between the two groups in this current study was wider than observed in the post-test, in favor of the worksheet group $\left(\rho=2.5 \times 10^{-12}\right)$. This value implies that the constructivist worksheet prompted and promoted the ability to recall learning tasks and events at various levels of particulate interaction even 2 to 3 weeks after treatment. Three trainees in the control group had conceptual challenges with writing correct names for some elements and compounds. After their second exercise, it became evident that the basic particles in reactants could not be easily identified by some of the teacher trainees, especially those in the control group. For example, if an item (question) required them to identify the constituent particles that were contained in each of some given reactants that were to go on to form a feasible chemical compound from a chemical reaction, they failed to identify the particles correctly. A typical example was when they had to identify the particles in silver chloride $(\mathrm{AgCl})$ and sodium nitrate $\left(\mathrm{NaNO}_{3}\right)$. The elements that could have been identified in silver chloride were silver and chlorine and the ions, silver ions and chloride ions. In the second reactant, they were to identify sodium (and its ions in a follow-up question) and then elements in the nitrate ion. Meanwhile, these posed challenges during class exercises. When asked to write the representative product, an even bigger challenge ensued. Formulae such as $\mathrm{Na}_{2} \mathrm{Cl}, \mathrm{NaCl}_{2}, \mathrm{Ag}_{2} \mathrm{NO}_{3}$, $\mathrm{Ag}\left(\mathrm{NO}_{3}\right)_{2}$, and many more which were not too popular among the trainees came up. The principle of conservation of matter was again not applied by some students, which implied that they had conceptual misunderstandings. Numbers of species in the reactant and product sides did not sum up for both sides of their equations.

It was discovered from trainees' introductory worksheets during the treatment sessions that they had challenges with interpreting diagrams mentally. They failed to decipher the kind and numbers of each species that could possibly be found in the sub-microstate. Neither could they clearly distinguish among pictorial representations of particulate 
elements, mixtures, and compounds by using their cores, as mentioned earlier. This state where students have to decode and recode sub-microscopic species is very critical during the formation of chemical compounds. Mental visualization of abstract concepts was a skill that needed to be developed. Teachers have to discuss diagrams and photographs in textbooks or study materials at length with their students so that they come to appreciate the contextual effects. The principle of conservation of matter was not applied in trainees' interpretations of models on their worksheets. Trainees' initial inabilities to relate the models on their worksheets to occurrences at the microscopic level of chemical reaction were evident. For learners of chemistry to represent and interpret chemical compounds as correctly as possible, they must understand the basic nature of chemical change that matter is always conserved. Therefore, species presented in reactants must again be observed in the same quantities in their products. They must also be familiar with symbols of elements, their names, and patterns of common combinations and their names. For example, some common predictive outcomes to learn with understanding could be such as the reaction between acids and metals, alkalis or metal carbonates, and their subsequent products, as well as proper representation in word and formula form. Besides, discerning distinctions among matter must be gained through practice.

Familiarity and understanding of scientific terms or language were also identified as a problem for both groups but especially for the control group. Concepts such as "element," "mixture," and "compound" had to be well understood for the trainees to be able to form a better understanding of the concept of "compound" through distinction. For example, a trainee defining or ascribing a reason for a product being a compound with the statement, "it is a compound because it is a substance/ product that consists of atoms of different elements joined together" is not definitive or distinctive enough. One would wonder what a mixture would be. Could the catchword for chemical compound be "different elements joined together"? Would teachers expect phrases like "chemically bound" to be more acceptable? One other shortcoming in that definition was that it was found not to include ionic materials. Therefore, it was important to give as much practice involving a variety of species to the teacher trainees and to ensure that, in each case, a "chemical reaction" was observed to have occurred, with correctly assigned reasons. This was found to be very important to facilitate the participants' understanding of reactions that result in compound formation. Obtained data from worksheets showed that components that learners invoke to make sense of properties of matter and chemical phenomena may change with sequenced and engaging tuition, but the underlying reasoning persists. Learners assume that observed tangible (macro) behaviors are dependent on the "types" of atoms present in a system and determined by those individual atom's inherent characteristics (Talanquer, 2017).

Chemical language is also specialized with governing rules that have evolved over the years, with their own meanings, functions, and syntax of chemical formulae, which cause problems for students. This was observed in how trainees failed to name chemical formulae of compounds that they had correctly discerned. Some of their naming errors resulted from strong mental associations between principles for naming binary compounds, trivial or familiar names, and lack of conceptual differentiation. Inability to properly differentiate between some formulae as was observed for the oxides of nitrogen and sulfur led the trainees to overlook the number of oxygen atoms attached to other central atoms, even as they paid undue attention to irrelevant entities during their naming tasks.

Through practice and group interactions, trainees in the experimental group were able to interpret diagrams appropriately, which subsequently facilitated their representational expressions from the MSE activities that they performed. Trainees in the control group, nevertheless, had to work extra hard to visualize and represent exactly what was happening at the microscopic level of reaction without much success, as they had no visual models and so failed to get their representational expressions of chemical reactions correct, especially in the retention test. This was enough to show that the worksheets had provided adequate forum for the experimental group to form mental images which they could fall on without practically engaging in laboratory activities. In this case, conceptual understanding was well developed; deep enough, to enable learners conceptualise in the abstract. This was because they were allowed and able to build and accommodate their own scientific concepts in a responsible, yet affable environment. Like other students in other parts of the world (Yan and Talanquer, 2015; Barke et al., 2009), trainees, in this study, had challenges with mental models and nomenclature of compounds as anionic parts of binary compounds were represented and named wrongly. If learners engage in learning by investigating, inquiring, collaborating, discussing, and forming mental models in multiple representational modes, they will learn more meaningfully and make conceptual gains, through distinction and the creation of patterns. Through the creation of patterns, learners' ideas could be organized into cohesive knowledge structures and reasoning schemas (Talanquer, 2017). It was also evident from the study that hands-on activities enhanced student learning.

Informal observations of the trainees at work showed that they were excited not only to work with the worksheets but also the MSE which was also a new concept that was introduced in the Chemistry and Physics Departments just before this current study. Studies by Hanson (2016), Sebuyira (2001), Supasorn (2015), and Zakaria et al. (2012) show that students who used micro equipment in other settings were excited and felt safe with their use, such that they disregarded fear of explosions as could occur from macrochemical activities. They saw these microactivities as fun and it engaged them in an interactive manner as the traditional tuition could not. This was what Hake (1998) meant when he said that lessons must be engaging and interactive for learners to form their own concepts in a non- 
tasking and friendly manner. Sometimes, predictions about the outcomes of chemical reactions that trainees had to perform before engaging in the microactivities were expected. After obtaining their experimental results, they had to compare them with their predictions and then compare them with theoretical results or models. This further enhanced their generalizations of how different compounds could be formed for application in new situations when no practical activities could be performed. Such "personal-formed" correct and authentic concepts are often held for long periods before learners forget them as was observed from the results of the experimental group's test scores in this study.

\section{CONCLUSIONS}

It was determined that teacher trainees had a number of misconceptions about how chemical compounds were formed for which remediation was attempted successfully. Basic concepts such as element, mixture, physical change, and chemical change had to be well understood for the concept "compound" as well as its underlying principles for its formation could be appreciated by trainees. The study supports earlier research that has revealed that many students struggle to understand chemical reactions. Students often have differentiation problems and over rely on basic oversimplified knowledge that must be extended and expanded. It was deduced that most of the trainees' cognitive structures for knowledge constructs and reasoning strategies were implicit as they exhibited representations of the properties of diverse types of chemical entities, events, processes, and states without attributing them to any particular pattern. Teachers must, therefore, develop clearer understanding of student reasoning as was attempted in this study.

The use of the activities in this study initiated reflective thinking skills in the teacher trainees. This enabled them to acknowledge some deficiencies in their naive idiosyncratic thinking processes about compound formation overtly and restructured them. This progress was because the trainees were able to gain visuality and tangibility (Say and Ozmen, 2018) not only through the worksheets but also through the practical activities (Sebuyira, 2001; Supasorn, 2015; Zakaria et al., 2012). Again, the activities increased the teacher trainees' retention spans, interest, and motivation for learning. Thus, the possibility of using worksheets to enhance conceptions about the formation of chemical compounds is favorable. The alternative conceptions identified in this study showed similar patterns with findings from related literature about students' conceptions of matter and its behaviour, which implies that it is a global problem that requires attention but could be solved using worksheets when all other modern technologies prove unattainable as was observed in this study. In this study, the teacher trainees showed interest and joy in the use of both microscale equipment and the worksheets, which together facilitated conceptual understanding of principles that govern the formation of chemical compounds; yet, a few conceptual difficulties persisted in their reasoning. Their explanations for chemical compounds were more of molecular than ionic models and so would require more laboratory practice, identification, and worksheet practice that involve ionic compounds.

\section{IMPLICATIONS}

This study has several implications for teaching and learning. It is important to note that the participants in this study were undergraduate students who were trained to become future teachers. Therefore, it was important that their own conceptions were identified and corrected early, if misconceptions existed, so that they would not transfer their wrong ideas and inefficiencies to their future students. It also has implications for chemistry curriculum developers and chemistry book writers so that they include more interactive and engaging activities in chemistry curricula and textbooks. Definitions of basic concepts which culminate into or form part of the conceptual framework for chemical compounds must be defined in diverse authentic ways so that learners gain "secure" conceptual models of each contributing concept. For example, terms such as elements, mixtures, physical change, chemical change, energy change, and a few more will have to be explained and connected in meaningful ways so that learners can also apply them appropriately in descriptions about the nature of matter. Besides these three suggestions, interactive strategies would have to be developed to teach chemical compound formation, as this topic forms one of the bedrocks of sound chemistry teaching and learning. Furthermore, the results are beneficial to educators who are particularly interested in conceptual development and learning progression.

No potential conflicts of interest were reported by the author.

\section{REFERENCES}

Barke, H.D., Hazari, A., \& Yitbarek, S. (2009). Misconceptions in Chemistry: Addressing Perceptions in Chemical Reactions. Berlin: Springer-Verlag.

Celikler, D. (2010). The effect of worksheets developed for the subject of chemical compounds on student achievement and permanent learning. The International Journal of Research in Teacher Education, 1(1), 42-51.

Chanyoo, W., Suwannoi, P., \& Treagust, D.F. (2018). A multi deimensional framework of conceptual change for developing chemical equilibrium learning. In: Yuenyong, C., Sangradit, T., \& Chatmaneerungcharoen, S. (Eds.), International Conference for Science Educators and Teachers (ISET) 2017 Proceedings. Taiwan: AIP Publishers. p19-23.

Demircioglu, G., Ayas, A., \& Demircioglu, H. (2005). Conceptual change achieved through a new teaching program on acids and bases. Chemistry Education Research and Practice, 6(1), 36-51.

Gebrekdian, T., Lykknes, A., \& Kvittingen, L. (2014). Small-scale chemistry for hands-on approach to chemistry practical work in secondary schools: Experiences from Ethiopia. African Journal of Chemical Education, 4(3), 48-94.

Hake, R.R. (1998). Interactive-engagement versus traditional methods: A six-thousand-student survey of mechanics test data for introductory physics course. American Journal of Physics, 66(1), 64-74.

Hanson, R. (2016). Using an embedded conceptual strategy to enhance students' understanding of Le Chatelier's summation of some stress factors on equilibrium position. International Journal for Cross Disciplinary Subjects in Education, 7(3), 2889-2899.

Hanson, R. (2017). In: Shoniregun, C.A., \& Akmayeva, G.A., (Eds.), Assessing the Potential of Worksheets as a Tool for Revealing Teacher Trainees' Conceptions about Chemical Bonds. CICE-2017 Proceedings. 
Mississauga, Canada: Infonomics Society. p648-653.

Hanson, R., Amedeker, M.K., Oppong, E., \& Antwi, V. (2011). Using microchemistry activities to improve preservice teachers' conceptions of some inorganic chemistry topics. International Journal of Educational Administration, 3(1), 19-40.

Hanson, R., Antwi, V., \& Ayim, G. (2017). The potential of integrating ICT into the teaching and learning of chemical bonds in senior high schools in Ghana a case study. International Journal of Scientific Research in Science and Technology, 3(3), 198-210.

Jones, L.L., \& Kelly, R.M. (2015). Visualization: The Key to Understanding Chemistry Concepts. Series, ACS Symposium. North Colorado: American Chemical Society Publications.

Kihwele, J.E. (2014). Students' perception of science subjects and their attitude in Tanzanian secondary schools. World Journal of Educational Research, 1(1), 1-8.

Sam, A., Niebert, K., Hanson, R., \& Aryeetey, C. (2016). Fusing scientists' conceptual correspondences to improve teaching of metal complex isomerism in higher education an educational reconstructive process. International Journal of Academic Research and Reflection, 4(1), 54-64.

Say, F.S., \& Ozmen, H. (2018). Effectiveness of concept cartoons on $7^{\text {th }}$ grade students' understanding of 'the structure and properties of matter'. Journal of Turkish Science Education, 15(1), 1-24.

Schnotz, W. (2014). An integrated model of text and picture comprehension. In: Mayer, R.E., (Ed.), The Cambridge Handbook of Multimedia Learning. New York: Cambridge University Press. p72-103.

Sebuyira, M. (2001). A Trial Introduction of RADMASTE Microchemistry Kits in Chemistry 1 Practical at the University of the Witwatersrand. South Africa: University of Witwatersrand, South Africa.

Supasorn, S. (2015). Grade 12 students' conceptual understanding and mental models of galvanic cells before and after learning by using small-scale experiments in conjunction wiyh a model kit. Chemical Education Research and Practice, 16, 393-407.
Talanquer, V. (2006). Commonsense chemistry: A model for understanding students' alternative conceptions. Journal of Chemical Education, 83(5), 811-816.

Talanquer, V. (2008). Students' predictions about the sensory properties of chemical compounds: Additive versus emergent frameworks. Science Education, 92(1), 96-114.

Talanquer, V. (2017). Progressions in reasoning about structure-property relationships. Chemistry Education, Research and Practice, 18(4), 559-571.

Toman, O.G., \& Ergen, Y. (2014). Determination of misconceptions belonging to the 'solar system and beyond: Space puzzle' unit in $7^{\text {th }}$ grade science and technology curriculum with two-tier diagnostic tests. International Journal of Trends in Arts, Sports and Science Education, 3(3), 58-64.

Vermette, P., Foote, C., Bird, C., Mesibov, D., Harris-Ewing, S., \& Battaglia, C. (2001). Understanding constructivism(s): A primer for parents and school board members. Education, 122(1), 87-93.

Yakmaci-Guzel, B., \& Adadan, E. (2013). Use of multiple representations in developing preservice chemistry teachers' understanding of the structure of matter. International Journal of Environmental and Science Education, 8(1), 109-130.

Yan, F., \& Talanquer, V. (2015). Students' ideas about how and why chemical reactions happen: Mapping the conceptual landscape. International Journal of Science Education, 37(18), 3066-3092.

Yildrim, N., Kurt, S., \& Ayas, A. (2011). The effect of worksheets on students' achievement in chemical equilibrium. Turkish Science Education, 8(3), 44-58.

Yitbarek, S. (2012). Low cost apparatus from locally available materials for the teaching of science. African Journal of Education, 2(1), 29-31.

Zakaria, Z., Latip, L., \& Tantayanon, S. (2012). Organic chemistry practices for undergraduates, using a small lab kit. Procedia Social and Behavioural Sciences, 59(1), 508-514.

\section{Appendix A: Pre-test/Post-test}

1. What particles (such as ions, atoms, and molecules) are present in sodium hydroxide and hydrochloric acid?

2. Aqueous sodium hydroxide reacts with aqueous hydrochloric acid to form.

3. What particles would be present after aqueous sodium hydroxide and hydrochloric acid react?

4. Would you say that a physical or chemical change has occurred?

5. Explain how the particles are bonded to each other. State the numbers of particles in the combinations.

6. Make a schematic or two-dimensional sketch of the reactants and products formed.

7. Write out the reaction in word and formula form.

\section{Appendix B: Abridged Retention test}

Write formula equations for the reactions below (1-4) and write the names of the resulting compound. Explain why you have formed your products of choice.

1. Trioxonitrate (v) acid reacts with aqueous calcium hydroxide.

From items $5-8$, fill in the missing species and explain your answer

4. Zinc carbonate.$+ \rightarrow$ Zinc sulfate

I write this answer because.

For items 9-10, choose one of the answers given and explain your choice

9. What are the products of the reaction between aqueous barium hydroxide and hydrochloric acid?
a. Barium chloride and water
c. Barium chloride and barium hydroxide
b. Barium hydroxide and water
d. Hydrochloric acid and barium

I make this choice because

10. Would you say that the change in Q9 is a physical or chemical process?

Explain: 


\section{Appendix C: Sample of Worksheet}

Complete the following word equations and explain your reason for supplying the missing components

1. Nitric acid $+\ldots \ldots \ldots \ldots . . . . \rightarrow$ potassium nitrate + water

2. Magnesium + dilute tetraoxosulfate (vi) acid $\rightarrow$

3. Calcium carbonate + hydrochloric acid (aq) $\rightarrow$.

4. Sodium + sulfur $\rightarrow$

5. Rubidium + salt solution $\rightarrow$

6. Acid + alkali $\rightarrow$

7. Interpret the figure below with respect to events at the particulate level:

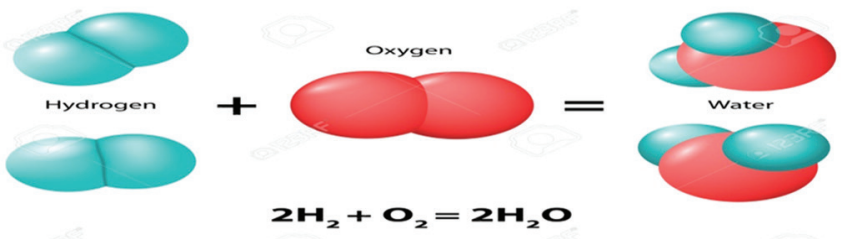

\section{Appendix D: Examples of daily class exercises}

1. Sodium reacts slower with water than potassium metal
i) True
ii) False

Reason

a) Sodium metal is smaller and so forms a second layer of water molecules around it, rendering it slow in reacting with water,

b) Potassium metal has a heavier mass and so reacts more vigorously with water,

c) The bonding in potassium metal is not as "tight" or compact as in sodium metal due to its large size,

d) Both sodium and potassium atoms have a valency of one but different sizes (sodium being smaller). Therefore, cohesive forces are stronger in sodium, thereby making it react less vigorously with water.

2. Predict whether aluminum would react faster or slower than magnesium with water.
i) Aluminum
ii) Magnesium

Reason

a) Aluminum will react faster than magnesium because it has a larger atomic number and more valence electrons,

b) Calcium will react faster than aluminum because it is bigger in size and has less valence elections,

c) Magnesium will react faster than aluminum. Reactivity of the elements with water increases down the group and decreases across a period. The factors which account for this are size, electronic configuration (valence electron), and nature of species concerned,

d) Aluminum will react faster than magnesium. Reactivity of the elements with water increases down the group and decreases across a period. The factors which account for this are size, electronic configuration (valence electron), and nature of species concerned.

In the following questions, you will be required to make a choice by placing a tick $(\sqrt{ })$ against a statement you think is correct and then justify the choice you have made in the space provided.

3. $\square \mathrm{Br}^{7+}$ is more stable than $\mathrm{Br}$

$\square \mathrm{Br}$ and $\mathrm{Br}$ are equally stable

$\square \mathrm{Br}$ is less stable than $\mathrm{Br}$

$\square$ I do not know

I make this choice because.

4. $\square \mathrm{Mg}^{2+}$ is more stable than $\mathrm{Mg}$

$\square \mathrm{Mg}^{2+}$ and $\mathrm{Mg}$ are equally stable

$\square \mathrm{Mg}^{2+}$ is less stable than $\mathrm{Mg}$

$\square$ I do not know

I make this choice because

5. Read the statement and choose whether a definition is correct or wrong. Decide if the definition is helpful and state why you made that choice: An element is a substance which cannot be split up into simpler substances. Is the definition correct? Would it help someone to understand?

$\square$ Yes

$\square$ No, it is wrong

$\square$ I am not sure

I make this choice because 


\section{Appendix E: Sample of tiered practical activity sheet}

How many drops were added? A [2]... A [3]:... Average:...

Q1. What is the volume/Ratio of aqueous sodium hydroxide to Acid A?

i) Repeat steps iii and iv in wells A [4] and A [5] but use B now instead of acid A. How many drops of aqueous sodium hydroxide did you add? Why did you have to add the said drops?

A [4]: A [5]: . Average:.

Q2. What is the volume ratio of $\mathrm{NaOH}(\mathrm{aq}) /$ Acid $\mathrm{B}$ ?

Q3. From your outcomes, what is the answer to the focus question above?

Q4. What can you conclude about acids A and B? Give possible molecular formulae for acids A and B.

Q5. Write and balance equations for the proposed reactions between the sodium hydroxide solution and acids A and B.

Q6. a. Find the amount of substance contained in $25 \mathrm{~cm}^{3}$ of $0.10 \mathrm{M} \mathrm{NaOH}$ (aq).

b. What would be the amount of substance contained in $25 \mathrm{~cm}^{3}$ of $0.10 \mathrm{M}$ acid B, if it should react with $25 \mathrm{~cm}^{3}$ of $0.10 \mathrm{M}$ $\mathrm{NaOH}(\mathrm{aq})$ ? Explain how you obtained the answer why it is so.

Q7. a. Explain the terms precision and accuracy.

b. Are the volumes of base used precise or accurate? Explain

Q8. If the average number of drops of base required to titrate 6 drops of acid A was experimentally determined to be 8 while the true value should have been exactly 6 , would the experimentally determined results be imprecise or accurate? Explain your choice in detail. 